\title{
The Dreaded Discussion: Ten Ways to Start
}

\section{Peter Frederick}

The only privilege a student had that was worth his claiming, was that of talking to the professor, and the professor was bound to encourage it. His only difficulty on that side was to get them to talk at all. He had to devise schemes to find what they were thinking about, and induce them to risk criticism from their fellows.

\section{- The Education of Henry Adams}

The conspiracy of silence is breaking up: we are learning to talk more openly about our joys and fears as teachers, our achievements and frustrations in the classroom. As I have listened to my colleagues talk about their students and their classrooms, the one fear and frustration mentioned more than any other, as for Henry Adams, was in leading a discussion. No matter how many articles on technique we read, or workshops we attend, the dreaded discussion continues to bother us more than any other part of our daily teaching lives. Freshman seminar and discussion-based core programs continue to develop. Pressures not only to "do more discussion" but to do it well, reinforced by student evaluations and faculty development centers, do not go away. We are learning, alas, that to walk into class and hold up one's copy of the assigned text, asking, "how'd you like it?" does not necessarily guarantee an enthusiastic, rewarding discussion.

We need, first of all, to acknowledge our fears in facing discussion classes: the terror of silences, the related challenges of the shy and dominant student, the overly-long dialogue between ourself and one combative student, the problems of digression and transitions, student fear of criticism, and our own fear of having to say "I don't know." 
Worst of all, perhaps, is the embarrassment of realizing, usually in retrospect, that "about half way through the period I lapsed, again, into lecture." I suspect that our fears about discussion (and our lapses) have a great deal to do with the issue of who controls the classroom. Although psychologically rooted, the control issue is best dealt with as a nitty-gritty practical question of how to plan and how to begin.

My first assumption is that an effective discussion, like most anything, depends upon good planning. The content goals for any given class period usually suggest employing different teaching strategies. We would like to be able to select form among many discussion possibilities with confidence. The purpose of this article is to expand the range of our options by describing very precisely several different ways of starting a discussion. Like Henry Adams, we "devise schemes" to find out what our students are thinking.

My particular schemes are guided by the following assumptions and principles about discussions:

- because we have much to learn from each other, all must be encouraged to participate

- it is important to devise ways in which each student has something to say, especially early in the class period

- students should be expected to do some (often highly structured) thinking about a text or issue before the discussion class begins

- students should know and feel comfortable with each other and with the teacher. As Carl Rogers and others keep reminding us, learning is aided perhaps most of all by the quality of personal relationships

- those relationships are enhanced by a climate of trust, support, acceptance, and respect: even "wrong" answers are legitimate

- a student's self-image is always affected by his or her participation in discussions: feedback, therefore, is crucial for self-esteem

- the primary goals in any discussion is to enhance the understanding of some common topic or "text" (in the broadest sense)

- different kinds of texts, purposes, and faculty teaching styles suggest using different kinds of discussion schemes.

My hope and expectation is that other teachers will adapt these suggestions and devise schemes for their own texts, purposes, and teaching styles. 
(1) GOALS AND VALUES TESTING: The students are asked to pair off and decide together what they think of the primary value of the particular text for the day, and how their consideration of it meshes with course goals. "Why are we reading this?" "Why now?" After five minutes or so, invite reactions. It is not necessary to hear from each pair, but hearing from a few provides a public reality test for the teacher's course goals ("is this text serving the purpose I had hoped it would?"), as well as providing a mutual basis for further probing into the text. An alternative initial question for the pairs is to ask for a list of relationships (comparisons and contrasts) between this text and another, usually the most recent one. Make the instructions explicit: "identify three themes common to both texts" "suggest the two most obvious differences between the two texts" "which did you like best and why?" "make a list of as many comparisons (or contrasts) as you can in ten minutes." In this case, in order to benefit from the richness of diversity, as well as to confirm similar insights, it is probably best to check in with each pair.

(2) CONCRETE IMAGES: It is obvious, of course, that discussions go better when specific references are made. Yet I think we often need help remembering the content of our text. A few minutes at the beginning can guarantee that the sophisticated analysis we seek will be based on specific facts. Go around the table and ask each student to state one concrete image/scene/event/moment from the text that stands out. No analysis is necessary-just recollections and brief description. As each student reports, the collective images are listed on the board, thus provides a visual record of selected content from the text as a backdrop to the following discussion. Usually the recall of concrete scenes prompts further recollections, and a flood of images flows from the students. A follow-up question is to invite the class to study the items on the board, and ask: "what themes seem to emerge from these items?" "what connects these images?" "is there a pattern to our recollected events?" "what is missing?" This is, obviously, an inductive approach to the text. Facts precede analysis. But also, everyone gets to say something early in class and every contribution gets written down to aid our collective memory and work.

(3) GENERATING QUESTIONS: We have our own important questions to ask about a text. And we should ask them. But students 
also have their questions and they can learn to formulate better ones. Being able to ask the right questions about a particular text may be the first way of coming to terms with it. There are many ways of generating questions:

A. Ask students ahead of time (Wednesday for Friday's class) to prepare one or two questions about their reading. One can vary the assignment by specifying different kinds of questions: open-ended, factual, clarifying, connective and relational, involving value conflicts, etc.

B. As students walk into the classroom ask them to write down (probably anonymously early in the term) one or two discussable questions about the text. "What questions/issues/problems do you want this group to explore in the next hour about this reading?" Hand all questions to one student (a shy one, perhaps) who, at random, selects questions for class attention. Do not expect to get through all of them, but the discussion of two or three questions usually will deal with or touch on almost every other one. Students, like all of us, ask questions they really want to answer themselves, and they will make sure their point is made somehow.

C. Same as B, except the teacher (or a student) takes a minute or two to categorize the questions and deals with them more systematically.

D. Ask each student to write down one or two questions (either ahead of time or at the start of class), but in this case the student owns his/her question and is in charge of leading the discussion until he/she feels there has been a satisfactory exploration of the issues. Start anywhere and go around the table. This obviously works best in smaller groups with longer periods than $\mathbf{5 0}$ minutes.

E. Divide the class into pairs or small groups and charge each group to decide upon one salient question to put to the rest of the class.

(4) FINDING ILLUSTRATIVE QUOTATIONS: We do not often enough go to the text and read passages out loud together. Students, we are told, do not know how to read any more. If so, they need to practice and to see modeled good old-fashioned explication de text. Ask each student, either ahead of time or at the start of class, to find one or two quotations from the assigned text that he/she found particularly significant. There are many ways in which the instructions 
may be put: "find one quotation you especially liked and one you especially disliked." Or, "find a quotation which you think best illustrates the major thesis of the piece." Or, "select a quote you found difficult to understand." Or, "find a quotation which suggests, to you, the key symbol of the larger text." After a few minutes of browsing (perhaps in small groups of three to four), the students will be ready to turn to specific passages, read out loud, and discuss. Be sure to pause long enough for everyone to find the right spot in their book: "starting with the middle paragraph on page sixty-one-are you all with us?" Lively and illuminating discussion is guaranteed because not all students will find the same quotations to illustrate various instructions, nor, probably, will they all interpret the same passages the same way. It is during this exercise that I have had the most new insights into texts I had read many times previously. And there may be no more exciting (or modeling) experience than for students to witness their teacher discovering a new insight and going through the process of refining a previously held interpretation. "Great class today! I taught Doc Frederick something he didn't know."

(5) BREAKING INTO SMALLER GROUPS: No matter the size of a class, sixty or six or one hundred and sixty, it can always be broken down into smaller groups of four, five, eight, fifteen, or whatever. The purpose, quite simply, is to enable more people to say something and to generate more ideas about a text or topic. Also, groups lend themselves usually to a lively, competitive spirit, whether asked to or not. We are interested not only in the few people we are grouped with but also in "what they're doing over there." Furthermore, reticent students often feel more confident in expressing themselves in a larger group after they have practiced the point with a safer, smaller audience. There are three crucial things to consider in helping small groups to work well. First, the instructions should be utterly clear, simple, and task-oriented. Examples: "Decide together which of the brothers is the major character in the novel." "Which person in the Iliad best represents the qualities of a Greek hero? Which person, the same or different, best represents a hero by your standards?" "Why did the experiment fail? What would you suggest changing?" "Identify the three main themes of this text." "What is Picasso's painting saying?" "Identify three positive and three negative qualities of King David's 
character." "What do you think is the crucial turning point in Malcom's life?" "If you were the company treasurer (lawyer), what decision would you make?" "Generate as big a list as you can of examples of sex role stereotyping in these first two chapters." "If you were Lincoln, what would you do?" In giving these instructions be sure to give the groups a sense of how much time they have to do their work. Second, I believe in varying the ways in which groups are formed in order to create different sized groups with different constituencies. Pair off ("with someone you don't know") one day; count off by fives around the room another; form groups of "about eight" around clumps of students sitting near one another on a third day. And third, vary the ways in which groups report out when reassembled. Variations include:

- each group reports orally, with the teacher recording the results (if appropriate) on the board

- each group is given a piece of newsprint and felt pen with which to record its decision, which are then posted around the room

- space is provided for each group, when ready, to write their results on the blackboard

- each group keeps notes on a ditto master, which the teacher runs off and distributes to everyone for continuing discussion the next meeting

- no reporting out is necessary, or reactions are invited from the several groups, but not necessarily from all of them.

Further possibilities for small groups are described in the suggestions that follow:

(6) GENERATING TRUTH STATEMENTS: This exercise develops critical skills and generates a good deal of friendly rivalry among groups. The instructions to each group are to decide upon three statements known to be true about some particular issue. "It is true about slavery that ..." "We have agreed that it is true about the welfare system that ..." "It is true about international politics in the 1950s that ..." "We know it to be true about the theory of relativity that..." And so on. I have found this strategy useful in introducing a new topicslavery, for example-where students may think they already know a great deal but the veracity of their assumptions demands examination. 
The complexity and ambiguity of knowledge is clearly revealed as students present their truth statements and other students raise questions about or refute them. The purpose of the exercise is to develop some true statements, perhaps, but mostly to generate a list of questions and of issues demanding further study. This provides an agenda for the unit. Sending students to the library is the usual next step, and they are quite charged up for research after the process of trying to generate truth statements.

(7) FORCED DEBATE: Although neither one of two polar sides of an issue obviously contains the whole truth, it is often desirable to force students to select one or the other of two opposite sided and to defend their choice. "Burke or Paine?" "Booker T. Washington or W.E.B. Du Bois?" "Are you for or against achieving racial balance in the schools? "Should Nora have left or stayed? "Who had the better argument: Creon or Antigone?" "Capitalism or Socialism for developing nations?" Once students have made their choice, which may be required prior to entering the room for class that day, I ask them to sit on one side of the table or room or the other to represent their decision. Physical movement is important and sides need to face each other. Once the students have actually, as it were, put their bodies on the line, they are more receptive to answering the question: "why have you chosen to sit where you are?" Inevitably, there may be some few students who absolutely refuse (quite rightly) to choose one side or the other. If they persist, with reasons, create a space for a middle position. This adds a dimension to the debate and, as in the case of deciding between Burke and Paine on whether or not to support the French Revolution, those in the middle find out what it is like to attempt to remain neutral or undecided in heated, revolutionary times. I also invite students to feel free to change their place during a debate if they are so persuaded, which adds still another real (and sometimes chaotic) aspect to the experience.

(8) ROLE PLAYING: This is a powerful learning strategy, guaranteed to motivate and animate most students and to confuse and make nervous many. Role playing is tricky. It can be as simple (deceptively so) as asking two members of the class to volunteer to adopt the roles of two characters from a novel at a crucial point in their relationship discussing how they feel about it, or what they should do next. Or two 
students can act out the President and an advisor some decision, or two slaves in the quarters at night discussing whether or not to attempt to run away, or a male and female (perhaps with reversed roles) discussing affirmative action or birth control. Issues involving value conflicts, moral choices, and timeless human dilemmas related to the students' world usually work best, but role playing need not be so personal. A colleague of mine in biology creates a student panel of foundation grant evaluators, before whom other students present papers and make research proposals. Or, as students walk into class and sit down, they find a card in front of them which indicates the name of a character from a novel, or an historical personage, or even a concept. For the discussion that follows they are to be the role indicated on their card. Knowing this might happen is not a bad motivator to make sure students get their reading done.

Any situation involving multiple group conflicts is appropriate for role playing. There are many simulation games for contemporary issues in the social sciences. But for history, I like to create my own somewhat less elaborate "games," putting students into the many roles represented in some historical event or period. One of my favorites is a New England town meeting in 1779 , in which a variety of groups (landed elite, yeoman farmers, Tory sympathizers, soldiers and riffraff, artisans, lawyers and ministers, etc.) are charged with drafting instructions for delegates to a state constitutional convention. Another is to challenge several groups in 1866-defeated Confederates, southern Unionists, northern Radical Republicans, northern moderates, and Black freedmen - to develop lists of goals and strategies for accomplishing them. I play an active role, as moderator of the town meeting or as President Johnson, organizing and monitoring the interactions that follow group causes. Our imagination can create many appropriate examples for role playing. You have, I am sure, your own.

But because role playing can be traumatic for some students and because a poorly-planned or poorly-monitored role play can get out of control, I want to make a few cautionary suggestions that I have found helpful, if not crucial. First, except for finding the cards at the beginning of class which compel playing a role, in most role playing activities students should have some choice in how much to participate, either by deciding whether or not to volunteer or by being part 
of a group large enough reduce the pressures on any one individual. Teachers should monitor carefully the unspoken signals of students who may find their role uncomfortable, and intervene, often by skillfully pursuing their own role, to extricate or reduce the pressures on an actor. Generally, however, I have found role playing to be an effective way for the normally shy student, who has said little or nothing in class, to unblock in the new role and participate more readily in conventional discussions afterwards. Second, give students some time (how much depends upon the nature of the particular role play) to prepare themselves for their role. This might mean two days or more in order to do some research, or fifteen minutes in groups to pool information, or five minutes to refresh one's memory about a character in a novel, or a couple of minutes simply to get in touch with the feelings of a character and situation. Third, in giving instructions the definition of roles to be played should be concrete and clear enough for students to get a handle on who they are playing, yet open enough for the expression of their own personality and interpretation. If the roles are prescribed too clearly, students merely imitate the character described (although sometimes this is the requirement) and have difficulty going beyond it with anything of themselves. If the roles are described too loosely, without a clear context, students will stray too far from the actual situation to be experienced and learned. And finally -and most importantly-in any role play experience as much (if not more) time should be devoted to debriefing afterwards as for the exercise itself. This is when the substantive lessons of the experience are discovered, explored, and confirmed. This is when those students who may have served as observers will offer their insights and analysis of what happened. Above all, this is when the actors will need an opportunity to talk about how they felt in their roles and what they learned, both about themselves and about the substantive issues involved.

(9) NON-STRUCTURED SCENE-SETTING: Most of the ways of starting a discussion described thus far involve a great deal of structure and direction. But inevitably, when teachers suspect that they have been dominating too much ("I blew it again-talked most of the hour!"), it is clearly time to give students an opportunity to take a discussion in their directions, and to do most, if not all, of the talking. 
The teacher, however, has a responsibility for setting the scene and getting class started. There are a variety of ways to do this, some more directive than others. Put some slides on a carousel and without a word, show them at the beginning of class. Or, as the students walk into the classroom, the teacher plays a piece of music or a speech on a tape recorder. Or, on the board before class the teacher writes a quotation or two, or two or three questions, or a list of words or phrases or names, or even an agenda of issues to be explored. The only necessary verbal instructions are to make it clear to the students that until a defined time (perhaps the last five minutes) you, the teacher, intend to stay out of the discussion entirely. Even having said that, I have still found that I am capable of breaking my own contract and intervening or, more likely, affecting the class by non-verbal signals. I tell my students that I find it extremely difficult to stay uninvolved, and that I need their help in making sure I stay out of the discussion. They are usually happy to oblige. If possible, adopt an utterly non-evaluative observer role and take descriptive notes back to the students may be the most helpful feedback you can give them.

(10) A TENTH WAY TO START: As the term progresses students will have experienced many different exciting ways to start a discussion, most of which, we hope, enhance their understanding of a text or issue. Once the expectation of variety has been established, there is even a legitimate place for the following strategy: stroll into class with your book, sit on the edge of the table, hold the book up, and ask: "how'd you like it?"

Although it has not been my primary purpose in this article to extol the many values of discussion, I assume that my bias has been implicitly clear. The key to effective retention of learning, I believe, is in owning the discovery. Emerson wrote in his journals that a wise person "must feel and teach that the best wisdom cannot be communicated (but) must be acquired by every soul for itself." My primary strategy as a teacher is to structure situations in which students have has many opportunities as possible to acquire wisdom for themselves; that is, to own the discovery of a new learning insight or connection and to express that discovery to others. In this way their substantive learning is increased and their self-esteem is enhanced. How we plan the start of class is crucial in achieving this goal. "Hey, roomie, I now 
know what Emerson meant by self-reliance. What I said in class about it today was that..." Which translated means: "Hey, I'm OK, I understand this stuff. I said something today others found helpful." Which translated means: "class was good today: he let me talk." 